\title{
Conservation challenges of sharks with continental scale migrations
}

\author{
Michelle R. Heupel ${ }^{1,2 *}$, Colin A. Simpfendorfer ${ }^{2}$, Mario Espinoza $^{3}$, Amy F. Smoothey ${ }^{4}$, Andrew Tobin ${ }^{2}$ \\ and Victor Peddemors ${ }^{4}$ \\ ${ }^{1}$ A Healthy and Resilient GBR, Australian Institute of Marine Science, Townsville, QLD, Australia \\ ${ }^{2}$ Centre for Sustainable Tropical Fisheries and Aquaculture, College of Marine and Environmental Sciences, James Cook University, Townsville, QLD, Australia \\ ${ }^{3}$ AIMS@JCU, Australian Institute of Marine Science, College of Marine and Environmental Sciences, James Cook University, Townsville, QLD, Australia \\ ${ }^{4}$ Fisheries New South Wales, NSW Department of Primary Industries, Sydney Institute of Marine Science, Mosman, NSW, Australia
}

\section{Edited by:}

Graeme Clive Hays, Deakin

University, Australia

\section{Reviewed by:}

Michael R. Heithaus, Florida

International University, USA

Richard Reina, Monash University,

Australia

Gail Schofield, Deakin University, Australia

Nuno Queiroz, CIBIO-UP - Research Center in Biodiversity and Genetic

Resources, Portugal

\section{*Correspondence:}

Michelle R. Heupel, A Healthy and Resilient GBR, Australian Institute of Marine Science, PMB No. 3,

Townsville, QLD 4810, Australia

e-mail:m.heupel@aims.gov.au
Understanding movement and connectivity of populations is increasingly important as human and climate change pressures become more pervasive, but can be problematic in difficult to observe species such as large marine predators. We examined the movements of bull sharks, Carcharhinus leucas, using acoustic telemetry arrays along the east coast of Australia. Approximately half of 75 individuals released in temperate waters moved into tropical reef regions, with both sexes undertaking long-range movements and multiple individuals making return trips. Only $3 \%$ of 39 individuals released in tropical reef habitats moved south to temperate waters, but approximately $25 \%$ moved to southern reef or subtropical coastal areas. These results reveal complex linkages along the east coast of Australia which suggest a tropical reef based population comprised of individuals that migrate to multiple regions. Connectivity between locations along the east coast of Australia creates important conservation challenges for resource managers in multiple jurisdictions.

Keywords: AATAMS, acoustic telemetry, Carcharhinus leucas, spatial management, connectivity

\section{INTRODUCTION}

High level consumers that move between different habitats and ecosystems (i.e., mobile link species as defined by Lundberg and Moberg, 2003) play disproportionately important roles in the stability and functioning of these systems (McCann et al., 2005). Mobile link species can play a wide array of ecological roles in both terrestrial and aquatic habitats, from spreading seeds and pollinating (Couvreur et al., 2004) to increasing the resilience of coral reefs (Nyström and Folke, 2001). Due to the high mobility of many species that function as mobile links these species are often subject to numerous management regimes including state, federal, and international policies (Lascelles et al., 2014). There are varying degrees of management success within and across these regimes, for example, protected area closures are thought to work for many species, but these areas are often too small to provide adequate protection at a population level (Lascelles et al., 2014). As such, the conservation and management of mobile species is important within an ecosystem context as well as at the population level (Russell et al., 2013). Within marine systems there are limited data on the movements of large top predators and the roles they play as mobile links in ecosystems because of the logistical challenges involved in their study. However, satellite and acoustic telemetry have increased the spatial resolution and understanding of when and where large marine predators move (Heupel et al., 2006; Block et al., 2011).

Management and conservation issues are critically important for species that move long distances, play a key ecological role in habitats, and are unlikely to benefit from spatial or regional management measures due to their movement patterns (Heupel et al., 2014). Species that move over long distances are also more likely to move between different jurisdictions, further complicating management and/or conservation efforts. Definition of the extent and occurrence of long-range movement and population connectivity is necessary for a full understanding of the ecology of a species and hence for designing effective conservation action. There are a number of marine species that undertake large movements with varying levels of understanding of the timing and location of these moves. Coastal marine mammals, reptiles, and fishes can undertake extensive oceanic and continental-scale movements related to biological requirements and resource needs (e.g., Limpus et al., 1992; Block et al., 2011; Hays et al., 2014; Jaine et al., 2014; Zeh et al., 2015). Sharks and rays represent one of the most diverse groups of large marine predators, and as such represent important functional groups within marine ecosystems. Their movement patterns are as diverse as their morphology. As concern about the global status of sharks and rays increases (Dulvy et al., 2014) understanding population connectivity is becoming an increasingly important topic.

Long-range movements are not uncommon in sharks (e.g., Holland et al., 1999; Weng et al., 2008; Sequeira et al., 2013), but knowledge of the extent and regularity with which these movements occur is often lacking. The bull shark, Carcharhinus leucas, is a common large neritic species that has been shown to be 
capable of long distance movements (Brunnschweiler et al., 2010; Carlson et al., 2010) based on limited satellite tagging. Recent research has indicated segregation by size may occur in C. leucas populations with smallest individuals using river habitats and largest individuals inhabiting marine regions (Simpfendorfer et al., 2005; Brunnschweiler and Barnett, 2013). Movements and habitat use by juvenile bull sharks has been well-documented in several studies (Heupel and Simpfendorfer, 2008; Heithaus et al., 2009; Heupel et al., 2010; Curtis et al., 2013), but data on adult movements are limited (Daly et al., 2014). In one of the few explorations of adult movement satellite tagged C. leucas were tracked moving distances of $2-1506 \mathrm{~km}$ (mean $143.6 \mathrm{~km}$ ) over periods up to 85 days in the Gulf of Mexico spending the majority of their time in warm, shallow coastal habitats (Carlson et al., 2010). Acoustic tracking in South Africa also recorded movements ranging from 433 to $709 \mathrm{~km}$ (mean $533 \mathrm{~km}$ ) over periods of $10-22$ months (Daly et al., 2014).

Here we investigated the movement of $C$. leucas along the east coast of Australia using acoustic monitoring to define long-range long-term movement behavior, implications of movement for population connectivity and the requirement for cross jurisdictional management. Bull sharks were chosen for this analysis due to their ability to undertake long range movements and exploit a wide range of habitats from rivers and estuaries to oceanic coral reefs. This plasticity results in a single species that can encounter various management regimes both inshore and offshore. Management arrangements for bull sharks vary between Queensland (QLD) and New South Wales (NSW), the two state jurisdictions of eastern Australia where bull sharks occur. The species is not protected in either jurisdiction, and both QLD and NSW target larger C. leucas in shark control programs at popular swimming beaches (Reid et al., 2011; Taylor et al., 2011). Catches in NSW commercial fisheries occur mostly in the Ocean Trap and Line Fishery where a longline fishery has targeted large sharks (Macbeth et al., 2009). Queensland commercial fisheries mostly take juvenile bull sharks in an inshore gillnet fishery that operates in estuarine areas (Harry et al., 2011). Both states have recreational fishing regulations that limit take to one bull shark per day, and in QLD only sharks less than $1.5 \mathrm{~m}$ can be taken. Queensland also has a series of Marine Parks [the Great Barrier Reef (GBR) Marine Park, the Great Sandy Marine Park, the Moreton Bay Marine Park] that limit or exclude fishing and other activities. No fishing and no entry zones would provide shelter for bull sharks from fishing pressure in these regions. Therefore, adult bull sharks moving along the east coast of Australia are exposed to a suite of management tools with varying degrees of protection. This presents a case study for examining conservation and management challenges for potentially exploited species.

\section{MATERIALS AND METHODS}

To examine the broad scale movement and connectivity of bull sharks along the east coast of Australia data were utilized from multiple acoustic receiver arrays covering a straight line distance of $2000 \mathrm{~km}$ : Sydney (Sydney Harbor and coastal areas) and the Clarence River in New South Wales (NSW), Moreton Bay, Lady Elliot Island, Capricorn Bunker reefs (Heron, Sykes,

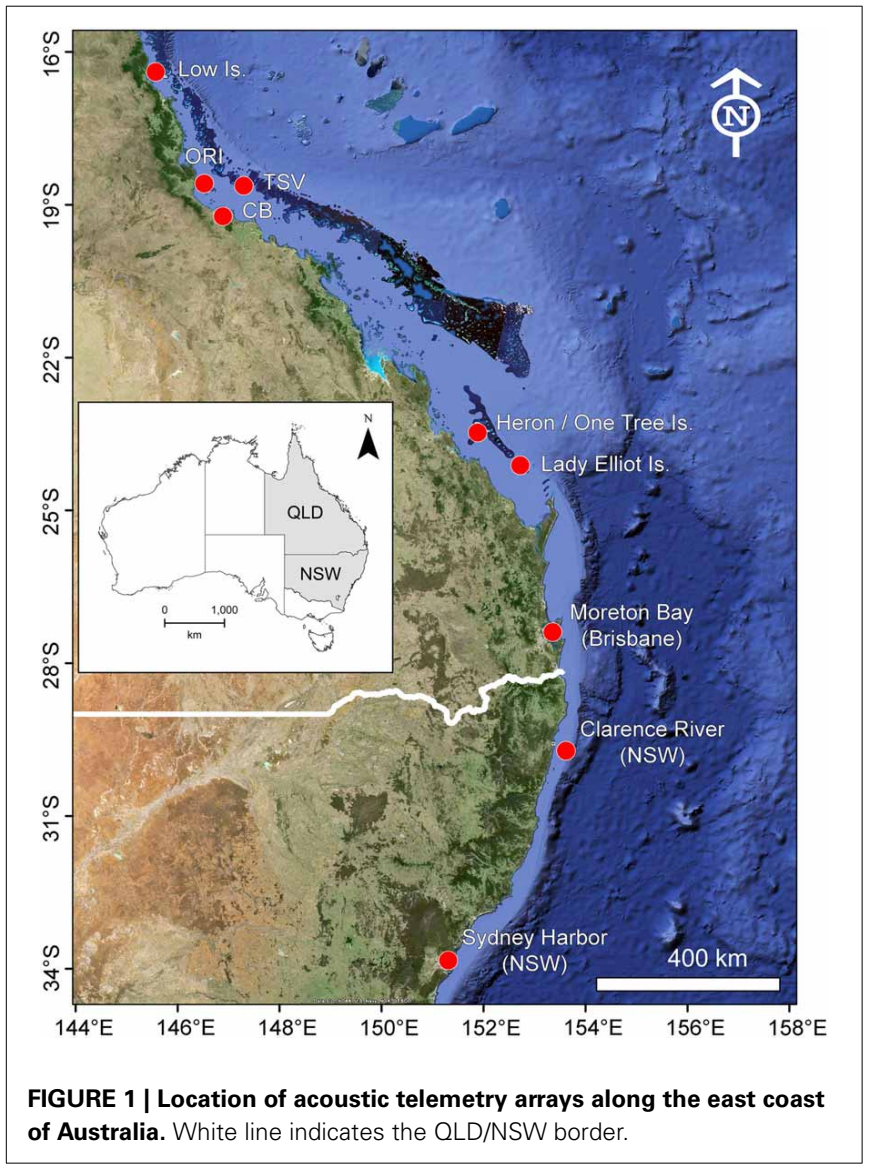

One Tree reefs), Cleveland Bay, Orpheus Island, a series of 17 reefs in the central GBR offshore from Townsville and Lowe Isles in Queensland (QLD) (Figure 1). Due to their proximity, data from Orpheus Island and the Townsville reefs were pooled as were Lady Elliot Island and Capricorn Bunker reefs. Each receiver array included Vemco VR2W acoustic receivers covering habitats as diverse as temperate estuaries, inshore seagrass regions, and offshore coral reefs. The number of receivers varied by site: Sydney (Harbor $=46$ and coastal areas $=16$ ), Clarence River $=$ 12 , Moreton Bay $=29$, Lady Elliot Island $=6$, Capricorn Bunker reefs $=50$, Cleveland Bay $=63$, Orpheus Island $=33$, the central $\mathrm{GBR}=56$, and Lowe Isles $=15$. The resulting combined network included 326 acoustic receivers along the east coast. Receiver arrays were deployed at various times with the earliest (Cleveland Bay) established in 2008. All arrays were deployed for the entire study period (2011-2014).

Sharks were captured using a variety of standard fishing methods including long lines and drop lines in NSW (Sydney Harbor and Clarence River) and QLD (Townsville reefs: Rib, John Brewer, Lodestone, Wheeler). All captured individuals were measured to the nearest $\mathrm{cm}$ total length (TL), sexed and a V16 acoustic transmitter surgically implanted using established methods (e.g., Heupel and Hueter, 2001). Transmitters were programmed on a pseudo-random repeat rate of 50-100 s (QLD) or 30-90 s (NSW) resulting in battery life of 824 and 3260 days, respectively. 


\section{DATA ANALYSIS}

Data from each of the acoustic arrays was either queried directly or obtained from the Australian Animal Tracking and Monitoring System online database (http://aatams.emii.org.au) for the presence of individuals released in NSW and QLD, and dates detected examined to define patterns of presence or visitation by site. The size and sex of individuals that remained near their tagging sites and those that moved between arrays or jurisdictions were compared via $t$-test and Chi-square analysis. The number of times individuals crossed the NSW-QLD border, and hence moved between management jurisdictions, were counted. Straight line distances between acoustic arrays were measured to indicate travel distance of individuals that moved between study sites.

To examine the level of shark connectivity between and within locations we used a modified circular plot, hereafter referred to as a connectivity plot. The connectivity plot represented the frequency and magnitude of daily shark movements, and therefore provided information about the incoming and outgoing movements of bull sharks at locations along the east coast of Australia. Connectivity plots were implemented using the "circos.trackPlotRegion" function from the "circlize" package (Gu et al., 2014) in R v.3.0.2 (R Development Core Team, 2005).

\section{RESULTS}

Data from 114 C. leucas were examined: 75 from NSW (33 female, 42 male) ranging in size from 80 to $322 \mathrm{~cm} \mathrm{TL}$ (mean: $211 \mathrm{~cm}$ ) and 39 from QLD (30 female, 9 male) ranging from 176 to $296 \mathrm{~cm}$ TL (mean: $244 \mathrm{~cm}$ ). Sex ratio of the originally tagged populations was not statistically different from 1:1 in NSW (chi-square $=1.14$, $d f=1, p=0.286$ ), but was in QLD (chi-square $=16.80, d f=1$, $p<0.001$ ) with a higher number of females present in this sample. Of this population 36 individuals from NSW (48\%; 16 female, 20 male) were detected by acoustic arrays in QLD while only one individual from QLD was detected in NSW (3\%). There was no significant difference in the sex ratio from 1:1 for NSW individuals detected in QLD (chi-square $=0.227, d f=1, p=0.634$ ). Due to the limited movement of QLD sharks across the border into NSW, all movement away from the Townsville reefs (south toward NSW) was examined. Ten individuals were detected moving away from the Townsville reefs including the individual detected in NSW. All of these individuals were female resulting in a significant sex bias in movement (chi-square $=12.54, d f=1$, $p<0.001)$.

There was a significant difference in the size of individuals that moved vs. those that remained near their tagging site in NSW $(t=-5.00, d f=60, p<0.001)$, while there was no significant difference for individuals in QLD $(t=0.30, d f=12$, $p=0.772)$. The mean size and standard deviation of individuals that remained in NSW was $172( \pm 86) \mathrm{cm}$ TL compared to 252 $( \pm 47) \mathrm{cm}$ TL for those that moved suggesting long-range movements may be restricted to older juveniles and adults. This result could not be tested in the QLD sample because the majority of individuals were large, with mean size of resident individuals 245 $( \pm 22) \mathrm{cm}$ TL compared to $241( \pm 36) \mathrm{cm}$ TL for individuals that moved.

Examination of the number of border crossings between NSW and QLD indicated individuals often moved back and forth between these jurisdictions. Seventeen individuals crossed the border once, moving into QLD and were not detected back in NSW. It is unclear if these individuals remained in QLD, moved to other regions, or returned to NSW but were not detected. The sex ratio of individuals exhibiting this pattern was nearly even $(53 \%$ female). Four individuals crossed the border twice (i.e., returned to NSW), 75\% of these were female. Thirteen individuals crossed the border three times with a slight male bias (69\%) in this category. One (male) and two ( 1 male, 1 female) individuals crossed the border four and five times, respectively. These results indicate varying patterns in movement potentially ranging from dispersal to philopatry to key sites with both sexes undertaking cross border movements.

Straight line dispersal distance of individuals that were detected at different arrays ranged from 60 to $1770 \mathrm{~km}$ (mean: $1194 \mathrm{~km}$ ) (Figure 2). Longest moves were made by 17 individuals traveling from Sydney Harbor to the northern end of the Townsville reefs array, an estimated $1770 \mathrm{~km}$ straight line distance (thus an underestimate). The next most common long distance move was from Sydney Harbor to the Capricorn Bunker reefs $(1150 \mathrm{~km})$ exhibited by nine individuals. Frequency and number of individuals undertaking long-range moves suggests this behavior was common.

In contrast, individuals captured in the Townsville reefs region showed more limited movements. One individual was detected in NSW (1690 km straight line distance) and returned to QLD. One individual (male) was recorded traveling further north to Low Isles. The remaining individuals moved a maximum distance of $1160 \mathrm{~km}$, with mean distance moved $788 \mathrm{~km}$ (i.e., the distance between Townsville and Capricorn Bunker reef regions). Moves within this population were most commonly to the Capricorn Bunker reefs $(n=8)$ or to inshore habitats such as Moreton Bay

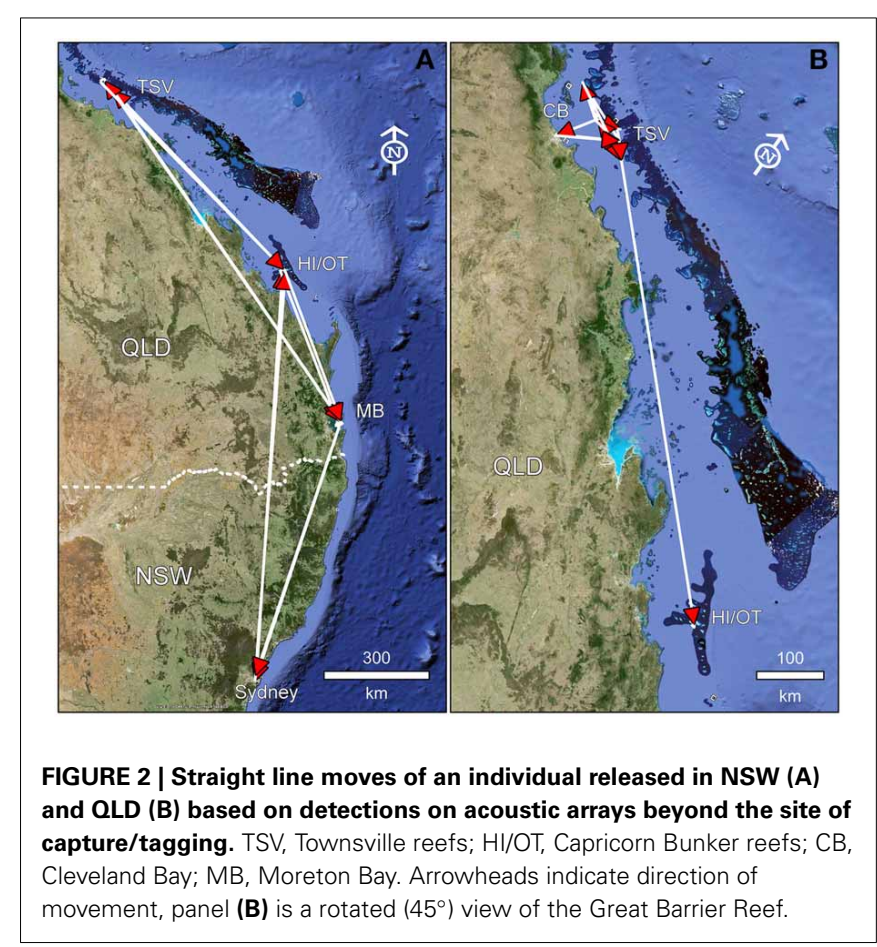


$(n=5)$ or Cleveland Bay $(n=3)$. Over $50 \%$ of the individuals tagged in the Townsville reefs region returned after detection in other areas.

The Orpheus Island/Townsville reefs region received the highest number of visits by individuals from NSW $(n=43)$. The Capricorn Bunker reefs were the next most frequent $(n=40)$, followed by Moreton Bay $(n=32)$ and Cleveland Bay $(n=3)$. Some repeated visits were evident. For example, 12 individuals visited the Capricorn Bunker reefs during December ( 5 female, 7 male). Of these individuals, five (all male) visited the Capricorn Bunker reefs in December in two or more of the study years indicating this region may be an important location at this time of year. All sites were visited during most months of the year, suggesting individuals reliably move alongshore in NSW and QLD with no apparent seasonality. Movements of sharks along the east coast of Australia revealed a high level of connectivity within and between sites (Figure 3). The frequency and magnitude of outgoing movements from Sydney Harbor (NSW) to Heron/One Tree Is and the Townsville reefs region were higher than incoming movements from these regions.

\section{DISCUSSION}

This analysis of shark movements has demonstrated that on the east coast of Australia C. leucas connect disparate tropical and temperate habitats and regularly cross jurisdictional boundaries. A number of mobile species have been reported to move or migrate along the east coast of Australia. This includes coastal residents such as turtles and dugongs (Limpus et al., 1992; Zeh et al., 2015), seasonal migrators such as humpback whales (e.g., Rock et al., 2006) and pelagic species such as marlin and manta rays (Gunn et al., 2003; Jaine et al., 2014). Movements of many of these species can be attributed to biological needs or access to resources. For example, manta ray movements have been correlated with oceanographic conditions such as eddies which may enhance foraging opportunities (Jaine et al., 2014). Black marlin also showed movement based on environmental conditions with individuals displaying distinct preferences for the mixed layer and specific temperatures (Gunn et al., 2003). While the drivers for C. leucas movement to and from coral reef regions are unknown, their position as high trophic level consumers suggest that they are likely playing an important role in both coastal and offshore coral reef environments (Daly et al., 2013). Linkages between inshore and offshore habitats created by these movements should be explored to better define the ecological role of bull sharks and how their movement patterns relate to other wide moving species along Australia's east coast.

Analysis documented repeated movements between study sites in NSW and QLD including movements of over $1700 \mathrm{~km}$ and

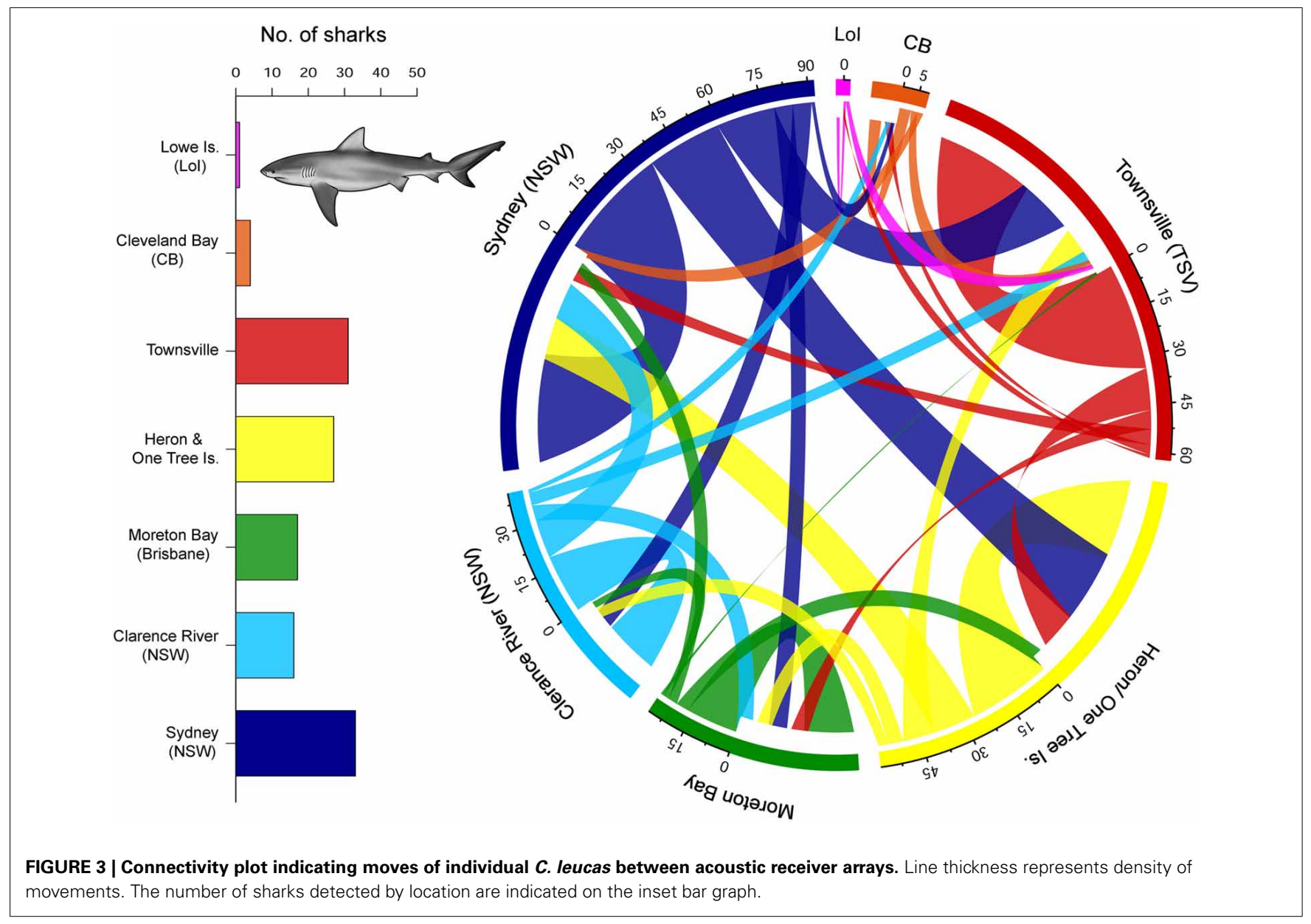


movement along the GBR. This result contrasts data from the Gulf of Mexico that documented mostly one way movements with an average distance of $140 \mathrm{~km}$ (Carlson et al., 2010). However, this previous research has been limited by the short-term nature of satellite-based telemetry in this species, and demonstrates the power of longer-term acoustic telemetry to detect seasonal and inter-annual migrations. Here individuals made return visits to both NSW and QLD, sometimes repeatedly, and showed fidelity to specific sites at discrete times. These results indicate movement patterns of C. leucas along the coast of Australia are purposeful and directed.

The majority of individuals undertaking long-range movements were large juveniles or adults. This result is consistent with suggestions that $C$. leucas partitions space use by size (Simpfendorfer et al., 2005) and may indicate an ontogenetic shift in behavior and habitat use. Adult movement away from inshore regions may be the result of changes in diet or resource needs, or could be a mechanism to reduce competition or avoid predation on kin. Recent research by Gleiss et al. (2015) has also suggested liver density may play a role in use of freshwater regions by elasmobranch species. It is thus possible that previously unconsidered biological drivers are also at work. Although large individuals were also detected in coastal bays, most visits were short in duration and/or in outer bay habitats distant from the rivers used by young individuals. One-way movements from NSW could also be the result of dispersal, high mortality in QLD, or inability to detect animals on their return. The lack of any distinct pattern by sex suggests movement was not driven only by reproductive behavior, although this cannot be ruled out. Sharks often display natal philopatry (Hueter et al., 2004; Feldheim et al., 2014) and it is possible that return trips to NSW or inshore bays by females may have been to give birth in their natal river. However, an absence of neonates in Sydney Harbor suggests this estuary was not functioning as an area for pupping, but could possibly be a location used for mating (Smoothey, unpublished data). This result differs from that of Daly et al. (2014) who reported distinct temporal movements in adult C. leucas, presumed to be driven by seasonal temperature changes.

The data from this research suggests that the GBR plays an important role in the ecology of adult C. leucas on the east coast of Australia. The disparity in the number of NSW tagged sharks that moved to the GBR compared to GBR tagged sharks that moved to NSW, suggest that the GBR region supports individuals from many parts of the east coast. Bull sharks have been reported from many systems in NSW and QLD (e.g., Harry et al., 2011; Werry et al., 2011), and the adults from all of these areas may spend time on the GBR. The current study was not intended to identify the role that the GBR plays in the ecology of C. leucas, but given the well-known role of rivers and estuaries as nursery areas for this species, and the size of the animals utilizing the GBR, it is likely that it may be an important foraging ground for adults. Previous research has indicated that juvenile C. leucas move to exploit pulsed resources (Matich and Heithaus, 2014) which may be a factor in the movement patterns here, although direct links to feeding on fish spawning aggregations cannot be made at this stage. As such, the potentially large number of individuals that occur on the GBR likely have a key role as large predators in coral reef environments. Studies of $C$. leucas in reef habitats in Fiji (Brunnschweiler and Barnett, 2013) would also support the theory that this species is a significant predator in coral reef environments. Thus, adult $C$. leucas would fit the definition of process links defined by Lundberg and Moberg (2003). Given that the GBR may be an important habitat for C. leucas from the entire east coast of Australia, and not just animals from QLD, their conservation within the GBR region may have broad geographic benefits.

Given the predictions that mobile link species play an important role in the stability and health of the ecosystems they connect, management and conservation of the C. leucas population is important throughout its range. Conservation is complicated by the large spatial scale of movement. There are a number or marine parks with no-fishing zones within the range of movements observed here, including the GBR Marine Park, the Great Sandy Marine Park, and the Moreton Bay Marine Park. While these parks offer some protection, the scale of C. leucas movements relative to the size of no-fishing areas suggest limited conservation benefits and hence additional management measures that are already in place, including catch limits and a maximum size limit of $1.5 \mathrm{~m}$, are likely justified (Heupel et al., 2014). Regular movement across state boundaries highlights the need for cooperation between jurisdictions to ensure sharks receive sufficient protection throughout their migrations. This may include the need for regulations related to the habitats in each jurisdiction where individuals spend time, as well as movement corridors (Pendoley et al., 2014). If shark movements extend beyond Australian Territorial waters international management arrangements and agreements also need to be considered as have been pointed out for several other migratory taxa (e.g., Hays et al., 2014; Lascelles et al., 2014; Pendoley et al., 2014). Therefore, the results of this study, and more extensive tracking of mobile species, are crucial to development of effective conservation and management policy. Currently the largest threats to adult C. leucas in eastern Australia are fishing activities including recreational and commercial fisheries (Macbeth et al., 2009), bather protection programs (Reid et al., 2011; Taylor et al., 2011), and habitat degradation (e.g., loss of mangrove habitat).

The results of this study have shown that continental scale acoustic telemetry systems can provide useful data on long-range movements and connectivity of broadly moving species. The importance of the GBR for adult bull sharks has not previously been reported, nor has the extent and regularity of large scale movement. These results highlight the complex challenges faced by managers when species move broadly and cross jurisdictional boundaries.

\section{ACKNOWLEDGMENTS}

We thank the Australian Animal Tagging and Monitoring System for their contribution of infrastructure and field support. The authors are grateful to A. Murray, O. Masens, M. Miller, D. Johnson, D. Young, and C. Gray for assistance with field work in NSW and J. Hazel for providing data from Lowe Isles. We also would like to thank J. Fabricio Vargas for the scientific drawing used in Figure 3. This research was conducted under research permits from NSW Fisheries, the Great Barrier Reef Marine Park 
Authority (G10/33754.1 and G10/33758.1) and animal ethics approvals Ref 07/08-CFC (NSW) and A1933 (QLD).

\section{REFERENCES}

Block, B. A., Jonsen, I. D., Jorgensen, S. J., Winship, A. J., Shaffer, S. A., Bograd, S. J., et al. (2011). Tracking apex marine predator movements in a dynamic ocean. Nature 475, 86-90. doi: 10.1038/nature10082

Brunnschweiler, J. M., and Barnett, A. (2013). Opportunistic visitors: long-term behavioural response of bull sharks to food provisioning in Fiji. PLoS ONE 8:e58522. doi: 10.1371/journal.pone.0058522

Brunnschweiler, J. M., Queiroz, N., and Sims, D. W. (2010). Oceans apart? Short-term movements and behaviour of adult bull sharks Carcharhinus leucas in Atlantic and Pacific Oceans determined from pop-off satellite archival tagging. J. Fish Biol. 77, 1343-1358. doi: 10.1111/j.1095-8649.2010. 02757.x

Carlson, J. K., Ribera, M., Conrath, C., and Heupel, M. R. (2010). Habitat use and movement patterns of bull sharks Carcharhinus leucas determined using pop-up satellite archival tags. J. Fish Biol. 77, 661-675. doi: 10.1111/j.10958649.2010.02707.x

Couvreur, M., Christiaen, B., Verheyen, K., and Hermy, M. (2004). Large herbivores as mobile links between isolated nature reserves trough adhesive seed dispersal. Appl. Veg. Sci. 7, 229-236. doi: 10.1111/j.1654-109X.2004. tb00614.x

Curtis, T. H., Parkyn, D. C., and Burgess, G. H. (2013). Use of human-altered habitats by bull sharks in a Florida nursery area. Mar. Coast. Fish. 5, 28-38. doi: 10.1080/19425120.2012.756438

Daly, R., Froneman, P.W., and Smale, M. J. (2013). Comparative feeding ecology of bull sharks (Carcharhinus leucas) in the coastal waters of the southwest Indian Ocean inferred from stable isotope analysis. PLoS ONE 8:e78229. doi: 10.1371/journal.pone.0078229

Daly, R., Smale, M. J., Cowley, P. D., and Froneman, P.W. (2014). Residency patterns and migration dynamics of adult bull sharks (Carcharhinus leucas) on the east coast of southern Africa. PLoS ONE 9:e109357. doi: 10.1371/journal.pone.0109357

Dulvy, N. K., Fowler, S. L., Musick, J. A., Cavanagh, R. D., Kyne, P. M., Harrison, L. R., et al. (2014). Extinction risk and conservation of the world's sharks and rays. eLife 3:e00590. doi: 10.7554/eLife.00590

Feldheim, K. A., Gruber, S. H., DiBattista, J. D., Babcock, E. A., Kessel, S. T., Hendry, A. P., et al. (2014). Two decades of genetic profiling yields first evidence of natal philopatry and long-term fidelity to parturition sites in sharks. Mol. Ecol. 23, 110-117. doi: $10.1111 / \mathrm{mec} .12583$

Gleiss, A. C., Potvin, J., Keleher, J. J., Whitty, J. M., Morgan, D. L., and Goldbogen, J. A. (2015). Mechanical challenges to freshwater residency in sharks and rays. J. Exp. Biol. doi: 10.1242/jeb.114868. [Epub ahead of print].

Gu, Z., Gu, L., Ellis, R., Schlesner, M., and Brors, B. (2014). Circlize implements and enhances circular visualization in R. Bioinformatics 30, 2811-2812. doi: 10.1093/bioinformatics/btu393

Gunn, J. S., Patterson, T. A., and Pepperell, J. G. (2003). Short-term movement and behaviour of black marlin Makaira indica in the Coral Sea as determined through a pop-up satellite archival tagging experiment. Mar. Freshw. Res. 54, 515-525. doi: 10.1071/MF03022

Harry, A. V., Tobin, A. J., Simpfendorfer, C. A., Welch, D. J., Mapleston, A., White, J., et al. (2011). Evaluating catch and mitigating risk in a multispecies, tropical, inshore shark fishery within the Great Barrier Reef World Heritage Area. Mar. Freshw. Res. 62, 710-721. doi: 10.1071/MF10155

Hays, G. C., Mortimer, J. A., Ierodiaconou, D., and Esteban, N. (2014). Use of long-distance migration patterns of an endangered species to inform conservation planning for the world's largest marine protected area. Conserv. Biol. 28, 1636-1644. doi: 10.1111/cobi.12325

Heithaus, M. R., Delius, B. K., Wirsing, A. J., and Dunphy-Daly, M. M. (2009). Physical factors influencing the distribution of a top predator in a subtropical oligotrophic estuary. Limnol. Oceanogr. 54, 472-482. doi: 10.4319/lo.2009.54.2.0472

Heupel, M. R., and Hueter, R. E. (2001). "Use of a remote acoustic telemetry system to monitor shark movements in a coastal nursery area," in Electronic Tagging and Tracking in Marine Fisheries, eds J. R. Sibert and J. L. Nielsen (Dordrecht: Kluwer Academic Publishers), 217-236. doi: 10.1007/978-94-0171402-0_10
Heupel, M. R., Knip, D. M., Simpfendorfer, C. A., and Dulvy, N. K. (2014). Sizing up the ecological role of sharks as predators. Mar. Ecol. Prog. Ser. 495, 291-298. doi: 10.3354/meps10597

Heupel, M. R., Semmens, J. M., and Hobday, A. J. (2006). Automated acoustic tracking of aquatic animals: scales, design and deployment of listening station arrays. Mar. Freshw. Res. 57, 1-13. doi: 10.1071/MF05091

Heupel, M. R., and Simpfendorfer, C. A. (2008). Influence of salinity on the distribution of young bull sharks in a variable estuarine environment. Aquat. Biol. 1, 277-289. doi: 10.3354/ab00030

Heupel, M. R., Yeiser, B. G., Collins, A. B., Ortega, L., and Simpfendorfer, C. A. (2010). Long-term presence and movement patterns of juvenile bull sharks, Carcharhinus leucas, in an estuarine river system. Mar. Freshw. Res. 61, 1-10. doi: 10.1071/MF09019

Holland, K. N., Wetherbee, B.M., Lowe, C. G., and Meyer, C. G. (1999). Movements of tiger sharks (Galeocerdo cuvier) in coastal Hawaiian waters. Mar. Biol. 134, 665-673. doi: $10.1007 / \mathrm{s} 002270050582$

Hueter, R. E., Heupel, M. R., Heist, E. J., and Keeney, D. B. (2004). The implications of philopatry in sharks for the management of shark fisheries. J. Northwest Atl. Fish. Sci. 35, 239-247. doi: 10.2960/J.v35.m493

Jaine, F. R. A., Rohner, C. A., Weeks, S. J., Couterier, L. I. E., Bennett, M. B., Townsend, K. A., et al. (2014). Movements and habitat use of reef manta rays off eastern Australia: offshore excursions, deep diving and eddy affinity revealed by satellite telemetry. Mar. Ecol. Prog. Ser. 510, 73-86. doi: 10.3354/meps10910

Lascelles, B., Notarbartolo Di Sciara, G., Agardy, T., Cuttelod, A., Eckert, S., Glowka, L., et al. (2014). Migratory marine species: their status, threats and conservation management needs. Aquat. Conserv. 24, 111-127. doi: 10.1002/aqc.2512

Limpus, C. J., Miller, J. D., Parmerter, C. J., Reimer, D., McLachlan, N., and Webb, R. (1992). Migraton of green (Chelonia mydas) and loggerhead (Caretta caretta) turtles to and from eastern Australian rookeries. Wildl. Res. 19, 347-358. doi: 10.1071/WR9920347

Lundberg, J., and Moberg, F. (2003). Mobile link organisms and ecosystem functioning: implications for ecosystem resilience and management. Ecosystems 6, 87-98. doi: 10.1007/s10021-002-0150-4

Macbeth, W. G., Geraghty, P. T., Peddemors, V. M., and Gray, C. A. (2009). Observer Based Study of Targeted Commercial Fishing for Large Shark Species in Waters off Northern New South Wales. NSW Fisheries Final Report Series No. 114 Industry and Investment NSW, Cronulla, NSW.

Matich, P., and Heithaus, M. R. (2014). Multi-tissue stable isotope analysis and acoustic telemetry reveal seasonal variability in the trophic interactions of juvenile bull sharks in a coastal estuary. J. Anim. Ecol.83, 199-213. doi: $10.1111 / 1365-2656.12106$

McCann, K. S., Rasmussen, J. B., and Umbanhowar, J. (2005). The dynamics of spatially coupled food webs. Ecol. Lett. 8, 513-523. doi: 10.1111/j.14610248.2005.00742.x

Nyström, M., and Folke, C. (2001). Spatial resilience of coral reefs. Ecosystems 4, 406-417. doi: 10.1007/s10021-001-0019-y

Pendoley, K. L., Schofield, G., Whittock, P. A., Ierodiaconou, D., and Hays, G. C. (2014). Protected species use of a coastal marine migratory corridor connecting marine protected areas. Mar. Biol. 161, 1455-1466. doi: 10.1007/s00227-0142433-7

R Development Core Team. (2005). R: A Language and Environment for Statistical Computing.

Reid, D. D., Robbins, W. D., and Peddemors, V. M. (2011). Decadal trends in shark catches and effort from the New South Wales, Australia, Shark Meshing Program 1950-2010. Mar. Freshw. Res. 62, 676-693. doi: 10.1071/ MF10162

Rock, J., Pastene, L. A., Kaufman, G., Forestell, P., Matsuoka, K., and Allen, J. (2006). A note on East Australia Group V Stock humpback whale movement between feeding and breeding areas based on photo-identification. J. Cetacean Res. Manage. 8, 301-305.

Russell, D. J. F., McConnell, B., Thompson, D., Duck, C., Morris, C., Harwood, J., et al. (2013). Uncovering the links between foraging and breeding regions in a highly mobile mammal. J. Appl. Ecol. 50, 499-509. doi: 10.1111/13652664.12048

Sequeira, A. M. M., Mellin, C., Meekan, M. G., Sims, D. W., and Bradshaw, C. J. A. (2013). Inferred global connectivity of whale shark Rhincodon typus populations. J. Fish Biol. 82, 367-389. doi: 10.1111/jfb.12017

Simpfendorfer, C. A., Freitas, G. G., Wiley, T. R., and Heupel, M. R. (2005). Distribution and habitat partitioning of immature bull sharks 
(Carcharhinus leucas) in a southwest Florida estuary. Estuaries 28, 76-83. doi: 10.1007/BF02732755

Taylor, S., Sumpton, W., and Ham, T. (2011). Fine-scale spatial and seasonal partitioning among large sharks and other elasmobranchs in southeastern Queensland, Australia. Mar. Freshw. Res. 62, 638-647. doi: 10.1071/ MF10154

Weng, K. C., Foley, D. G., Ganong, J. E., Perle, C., Shillinger, G. L., and Block, B. A. (2008). Migration of an upper trophic level predator, the salmon shark Lamna ditropis, between distant ecoregions. Mar. Ecol. Prog. Ser. 372, 253-264. doi: 10.3354/meps07706

Werry, J. M., Lee, S. Y., Otway, N. M., Hu, Y., and Sumpton, W. (2011). A multifaceted approach for quantifying the estuarine-nearshore transition in the life cycle of the bull shark, Carcharhinus leucas. Mar. Freshw. Res. 62, 1421-1431. doi: 10.1071/MF11136

Zeh, D. R., Heupel, M. R., Limpus, C. J., Hamann, M., Fuentes, M. M. B. P., Babcock, R. C., et al. (2015). Is acoustic tracking appropriate for air-breathing marine animals? Dugongs as a case study. J. Exp. Mar. Biol. Ecol. 464, 1-10. doi: 10.1016/j.jembe.2014.11.013
Conflict of Interest Statement: The authors declare that the research was conducted in the absence of any commercial or financial relationships that could be construed as a potential conflict of interest.

Received: 20 November 2014; accepted: 06 February 2015; published online: 24 February 2015.

Citation: Heupel MR, Simpfendorfer CA, Espinoza M, Smoothey AF, Tobin A and Peddemors $V$ (2015) Conservation challenges of sharks with continental scale migrations. Front. Mar. Sci. 2:12. doi: 10.3389/fmars.2015.00012

This article was submitted to Marine Megafauna, a section of the journal Frontiers in Marine Science.

Copyright (c) 2015 Heupel, Simpfendorfer, Espinoza, Smoothey, Tobin and Peddemors. This is an open-access article distributed under the terms of the Creative Commons Attribution License (CC BY). The use, distribution or reproduction in other forums is permitted, provided the original author(s) or licensor are credited and that the original publication in this journal is cited, in accordance with accepted academic practice. No use, distribution or reproduction is permitted which does not comply with these terms. 